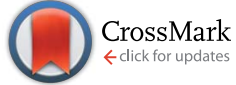

Cite this: J. Mater. Chem. A, 2016, 4, 4755

Received 9th December 2015

Accepted 5th February 2016

DOI: 10.1039/c5ta10032a

www.rsc.org/MaterialsA

\section{Ultrafast laser-assisted synthesis of hydrogenated molybdenum oxides for flexible organic solar cells $\uparrow$}

\begin{abstract}
Wan Jae Dong, Juyoung Ham, Gwan Ho Jung, Jun Ho Son and Jong-Lam Lee*
A novel method to synthesize a hydrogenated molybdenum oxide $\left(\mathrm{H}_{y} \mathrm{MoO}_{3-x}\right)$ thin film by irradiation of photons using a $\mathrm{KrF}$ laser $(\lambda=248 \mathrm{~nm})$ on an ammonium heptamolybdate $\left(\left(\mathrm{NH}_{4}\right)_{6} \mathrm{Mo}_{7} \mathrm{O}_{24} \cdot 4 \mathrm{H}_{2} \mathrm{O}\right)$ precursor layer is demonstrated. The laser-assisted synthesis is simple, and can be conducted in an ambient atmosphere without damaging the underlying bottom electrode and plastic substrate. The exposure time (30 ns) is extremely short compared to thermal annealing (>3 min). Because the highenergy photons are absorbed by the $\mathrm{MoO}_{3}$ layer and provide the activation energy for the reaction, the hydrogen atoms that dissociate from the ammonium molecules bond to the $\mathrm{MoO}_{3}$; this process yields a $\mathrm{H}_{y} \mathrm{MoO}_{3-x}$ thin-film. By controlling the laser energy, the stoichiometry of the $\mathrm{H}_{y} \mathrm{MoO}_{3-x}$ layer can be manipulated to simultaneously obtain advantageous electrical properties of both high work function (5.6 eV) and electrical conductivity $\left(9.9 \mu \mathrm{S} \mathrm{cm}{ }^{-1}\right)$. The $\mathrm{H}_{y} \mathrm{MoO}_{3-x}$ hole transport layer (HTL) is successfully demonstrated on flexible top-illuminated PTB7:PCBM organic solar cells (OSCs). This OSC has good mechanical flexibility, and 75\% higher short-circuit current than the device with a PEDOT:PSS HTL. Finite-domain time-difference simulations were conducted to verify the enhancement of the photocurrent. The thin layer of $\mathrm{H}_{y} \mathrm{MoO}_{3-x}$ was proven to be suitable for the microcavity condition which allows a resonant wavelength match to the PTB7:PCBM active layer.
\end{abstract}

\section{Introduction}

Transition metal oxides (TMOs) have possible applications as the hole transport layer (HTL) among various charge transport materials ${ }^{\mathbf{1 - 4}}$ in optoelectronic devices such as organic light-emitting diodes, ${ }^{6}$ organic solar cells (OSCs) ${ }^{5-8}$ and perovskite solar cells. ${ }^{9}$ Among TMOs, molybdenum oxide $\left(\mathrm{MoO}_{3}\right)$ is a promising candidate because of its transparency, air stability, and high work function (WF) ${ }^{10-27}$ In the early stages of OSC research, vacuumdeposition was conducted for the fabrication of $\mathrm{MoO}_{3}$ thin-films. However, as a large-area and low-cost roll-to-roll (R2R) fabrication has attracted attention for practical applications, a number of attempts have been conducted to obtain solution-processed $\mathrm{MoO}_{3}$ as a HTL in OSCs. ${ }^{10-18}$ Among the various properties of $\mathrm{MoO}_{3}$, good electrical conductivity is needed for the HTL. Oxygen vacancies play a key role in obtaining the conductivity of the $\mathrm{MoO}_{3}$ layer. Electrons fill up to the d-orbital, called gap states, as oxygen vacancies are produced. The occupied gap states make the Fermi level move near to the conduction band, thereby leading to an n-type semiconductor with increased electrical conductivity $(\sigma)$. Thus, finding an easy way to create oxygen vacancies in solution-processed $\mathrm{MoO}_{3}$ is critical to realize conducting $\mathrm{MoO}_{3}$

POSTECH, Material Science \& Engineering, Pohang, Republic of Korea. E-mail: jllee@ postech.ac.kr

$\dagger$ Electronic supplementary information (ESI) available. See DOI: $10.1039 / \mathrm{c} 5$ ta10032a for OSCs. The thermal annealing of ammonium molybdate at high temperature $\left(>160{ }^{\circ} \mathrm{C}\right)$ has been considered to produce oxygen vacancies through the decomposition of $\mathrm{MoO}_{3} \cdot{ }^{\mathbf{1 0 - 1 2}}$ The performance of OSCs with thermally annealed ammonium molybdate was better than that of devices using poly(ethylenedioxythiophene):poly(styrenesulfonate) (PEDOT:PSS). However, the high-temperature heat treatment not only caused a severe aggregation but also damages the plastic substrate on which flexible OSCs are fabricated. ${ }^{\mathbf{1 0 , 1 2}}$ In order to reduce the annealing temperature $\left(<120^{\circ} \mathrm{C}\right)$ to protect the plastic substrate, several low-temperature precursors and processing methods have been conducted.

One method is to use hydrogen molybdenum bronzes, synthesized by dissolving Mo powder in hydrogen peroxide at room temperature. ${ }^{14-16}$ The other method is to use ammonium heptamolybdate as an inexpensive precursor for low-temperature processing $\left(100{ }^{\circ} \mathrm{C}\right) .{ }^{17,18}$ These methods, however, require long processing times to obtain conductivity, leading to restraint from the employment of R2R processes for OSCs. Furthermore, it is hard to implement a micro-pattern on the solution-processed $\mathrm{MoO}_{3}$ due to several steps in patterning for the implementation of devices.

In this paper, a low-temperature, and ultrafast method to produce solution-processed $\mathrm{MoO}_{3}$ is demonstrated using $\operatorname{KrF}$ laser $(\lambda=248 \mathrm{~nm}, 5.0 \mathrm{eV})$ irradiation. The laser provides advantages because patterning can be simultaneously achieved by direct writing. High-density monochromatic photons 
are absorbed by an ammonium heptamolybdate $\left(\left(\mathrm{NH}_{4}\right)_{6}\right.$ $\left.\mathrm{Mo}_{7} \mathrm{O}_{24} \cdot 4 \mathrm{H}_{2} \mathrm{O}\right)$ thin-film and rapidly activate the reaction between ammonium molecules and $\mathrm{MoO}_{3}$. This solid-state chemical reaction occurs in 30 ns. The laser energy changes the stoichiometry and electronic band structure of the solution-processed $\mathrm{MoO}_{3}$ film, thereby resulting in both a high WF $=5.6 \mathrm{eV}$ and high $\sigma=9.9 \mu \mathrm{S} \mathrm{cm}{ }^{-1}$. When the laser-assisted reaction is conducted for the preparation of HTLs in PTB7:PCBM-based OSCs, the annealing time is shortened by $10^{9}$ times that of the conventional thermal annealing process. Moreover, the laser-irradiated $\mathrm{MoO}_{3} \mathrm{HTL}$ is proven to be effective in light trapping in the flexible top-illuminated OSCs, thereby resulting in a short-circuit current enhancement by $75 \%$ compared to the device with PEDOT:PSS. This flexible OSC showed no change in photo conversion efficiency (PCE) after 5000 bending cycles at a bending radius of $0.48 \mathrm{~cm}$.

\section{Experimental}

\subsection{Preparation of the $\mathrm{MoO}_{3}$ solution}

The $\mathrm{MoO}_{3}$ solution was prepared by dissolving ammonium molybdate tetrahydrate $\left(\left(\mathrm{NH}_{4}\right)_{6} \mathrm{Mo}_{7} \mathrm{O}_{24} \cdot 4 \mathrm{H}_{2} \mathrm{O}\right.$, Aldrich, $99.98 \%$, $0.1 \mathrm{~g}$ ) in $100 \mathrm{ml}$ of deionized water.

\subsection{Fabrication of PTB7:PCBM organic solar cells}

Glass coated with ITO (150 nm thick, $\left.\sim 10 \Omega \mathrm{sq}^{-1}\right)$ was used as the starting substrate. It was treated using UV-ozone for $15 \mathrm{~min}$ followed by coating with the $\mathrm{MoO}_{3}$ solution at $4000 \mathrm{rpm}$ for $40 \mathrm{~s}$. The resulting $\mathrm{MoO}_{3}$ thin-film was irradiated at laser energies of $120,240,400$ or $600 \mathrm{~mJ} \mathrm{~cm}^{-2}$, using a $\mathrm{KrF}$ excimer laser $(\lambda=248$ $\mathrm{nm}$, frequency $=2 \mathrm{~Hz}$, size $=0.25 \mathrm{~cm}^{2}$ ). To fabricate the control device, a PEDOT:PSS layer was spin-coated at $3000 \mathrm{rpm}$ for $30 \mathrm{~s}$, then dried at $120{ }^{\circ} \mathrm{C}$ for $10 \mathrm{~min}$. After samples were coated with the HTL, they were transferred to an $\mathrm{N}_{2}$-filled glove box $\left(<0.1\right.$ ppm $\mathrm{O}_{2}$ and $\mathrm{H}_{2} \mathrm{O}$ ). PTB7 (purchased from 1-materials) was dissolved in chlorobenzene to make a $10 \mathrm{mg} \mathrm{ml}^{-1}$ solution, then blended with $\mathrm{PC}_{70} \mathrm{BM}(2: 3 \mathrm{w}: \mathrm{w})$. The blend was spin-coated (1600 rpm, $30 \mathrm{~s}$ ) on top of the HTL. The thickness of the active layer was $80 \mathrm{~nm}$ as measured using an Alpha step 500 surface profiler. The cathode consisted of BCP (15 nm) coated with Ag (120 nm), which was deposited using a thermal evaporation method at a base pressure of $2 \times 10^{-6}$ Torr.

\subsection{Fabrication of flexible top-illuminated organic solar cells}

Reflective Ag (120 nm) and ITO (20 nm) were deposited on the PES film by radio-frequency sputtering under a base pressure of $1 \times 10^{-6}$ Torr. The films were treated with UV-ozone for $10 \mathrm{~min}$, then coated with $\mathrm{MoO}_{3}$ solution. The resulting $\mathrm{MoO}_{3}$ layer was exposed to the laser with an energy of $240 \mathrm{~mJ} \mathrm{~cm}^{-2}$. After the HTL was applied, the active layer of PTB7:PCBM was coated by spin coating. The devices were dried on a hot plate in a glove box at $80{ }^{\circ} \mathrm{C}$ for $10 \mathrm{~min}$. The transparent cathode (BCP $(15 \mathrm{~nm}) / \mathrm{Ag}$ $(12 \mathrm{~nm}) / \mathrm{MoO}_{3}(40 \mathrm{~nm})$ ) was deposited using thermal evaporation at a base pressure of $2 \times 10^{-6}$ Torr.

\subsection{Optical simulation}

The finite-domain time-difference (FDTD) simulation (fullwave) was performed for numerical analysis of the light absorption and field distribution in the polymer solar cells. The side-wall of the photo-detector was composed of a perfect mirror and the grid size was fixed to $2 \mathrm{~nm}$.

\subsection{Characterization}

The $\mathrm{MoO}_{3}$ solution was spin-coated on the silicon substrate, followed by measuring of the thickness using a spectroscopic ellipsometer. The measured data was fitted using the Lorentz function, thereby resulting in a thickness of $3 \mathrm{~nm}$. The FT-IR spectra were measured using a Bruker IFS 66v FT-IR spectrometer. The X-ray photoelectron spectroscopy (XPS) and ultraviolet photoelectron spectroscopy (UPS) were conducted on the $4 \mathrm{D}$ beam line at the Pohang Accelerator Laboratory with a base pressure of $5 \times 10^{-10}$ Torr. AFM images were obtained in tapping mode on a Veeco Nanoscope III. An ITO $(150 \mathrm{~nm}) / \mathrm{H}_{y^{-}}$ $\mathrm{MoO}_{3-x} / \mathrm{Ag}(120 \mathrm{~nm})$ structure was fabricated for the measurement of electrical conductivity of $\mathrm{H}_{y} \mathrm{MoO}_{3-x}$. The conductivity was averaged over 40 samples for each of the treatment conditions. The $J-V$ curves were measured under air ambient using a Keithley 2400 source measurement unit. The photocurrent was measured under AM $1.5 \mathrm{G} 100 \mathrm{~mW} \mathrm{~cm}^{-2}$ illumination from an Oriel $150 \mathrm{~W}$ solar simulator. The light intensity was determined using a mono-silicon detector calibrated by the U.S. National Renewable Energy Laboratory (NREL). The incident photon to current efficiency (IPCE) was measured using a QEX10 Solar Cell Quantum Efficiency Measurement System (PV Measurements, Inc.). The integral of the IPCE curve measured under air mass 1.5 of the solar irradiance spectrum is

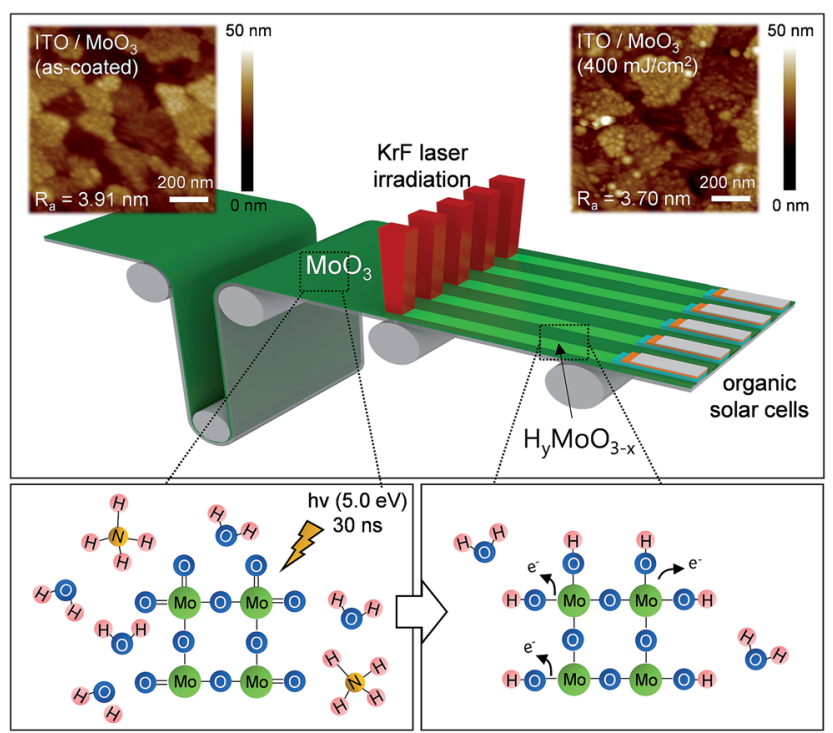

Fig. 1 Schematic illustration of the laser-assisted synthesis of the hydrogenated $\mathrm{MoO}_{3}$ hole transport layer for flexible organic solar cells. Inset: atomic force microscope images of $\mathrm{MoO}_{3}$ and laser-irradiated $\mathrm{MoO}_{3}$. 
a little smaller than the measured $J_{\text {sc }}$ because the IPCE measurement cannot measure the wavelength below $400 \mathrm{~nm}$.

\section{Results and discussion}

\subsection{Reduction mechanism and chemical composition}

The reaction of solution-processed ammonium heptamolybdate $\left(\left(\mathrm{NH}_{4}\right)_{6} \mathrm{Mo}_{7} \mathrm{O}_{24} \cdot 4 \mathrm{H}_{2} \mathrm{O}\right)$ (Fig. 1) involves the coating of a solutionprocessed $\mathrm{MoO}_{3}$ layer onto an ITO-deposited substrate, followed by irradiation using the $\mathrm{KrF}$ excimer laser. Due to the relatively small bandgap $(3.3 \mathrm{eV})$ of the $\mathrm{MoO}_{3}$ layer, ${ }^{14}$ the incoming photons are absorbed and heat is generated by the non-radiative recombination of electron-hole pairs. This thermal energy rapidly activates the reaction between $\mathrm{MoO}_{3}$ and surrounding $\mathrm{NH}_{4}{ }^{+}$molecules. The surface morphology of the ascoated $\mathrm{MoO}_{3}$ layer and laser-irradiated $\mathrm{MoO}_{3}$ layers (Fig. 1, inset) have a similar root mean squared roughness of $3.91 \mathrm{~nm}$ and $3.70 \mathrm{~nm}$, respectively. However, when the substrate is irradiated with high energy of $600 \mathrm{~mJ} \mathrm{~cm}^{-2}$, cracks form in the ITO layer due to thermal shock (Fig. S1 $\dagger$ ). These cracks significantly increase the sheet resistance of the ITO electrode from 8 $\Omega \mathrm{sq}^{-1}$ to $120 \Omega \mathrm{sq}^{-1}$. The $\mathrm{MoO}_{3}$ layers spin-coated on the ITO electrode have high optical transmittance $\sim 84 \%$ regardless of laser irradiation (Fig. $\mathrm{S} 2 \dagger$ ); i.e., the irradiation did not affect its optical properties.

To identify the structure of the $\mathrm{MoO}_{3}$ thin-film, we performed Fourier transform infrared (FTIR) spectroscopy on several $\mathrm{MoO}_{3}$ samples after treatment using laser irradiation or thermal annealing (Fig. 2a). The as-coated $\mathrm{MoO}_{3}$ layer showed two distinct absorption bands at $949 \mathrm{~cm}^{-1}$ and $883 \mathrm{~cm}^{-1}$. The band at $949 \mathrm{~cm}^{-1}$ is assigned to the stretching vibration of terminal oxygen $(\nu \mathrm{O}=\mathrm{Mo})$. The peak at $883 \mathrm{~cm}^{-1}$ is attributed to the Mo-O-Mo vibrations of $\mathrm{Mo}^{6+}$ for the stoichiometric $\mathrm{MoO}_{3}{ }^{28-30}$ When the $\mathrm{MoO}_{3}$ layer was irradiated with photons with mild energy $\left(120 \mathrm{~mJ} \mathrm{~cm} \mathrm{~cm}^{-2}\right)$, a new band at $1074 \mathrm{~cm}^{-1}$ and broad band at $1120-1350 \mathrm{~cm}^{-1}$ appeared, due to the vibration

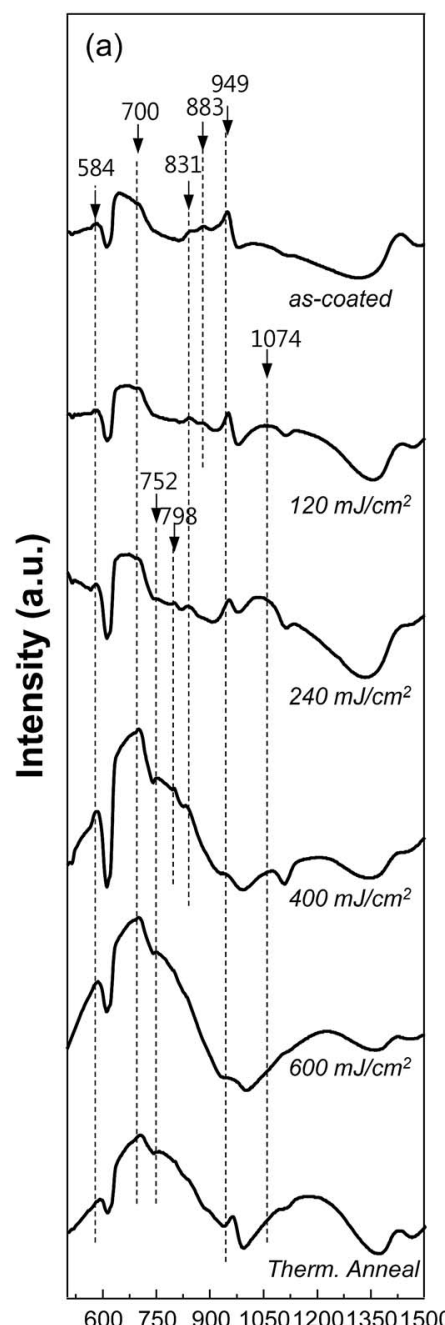

Wavelength $\left(\mathrm{cm}^{-1}\right)$
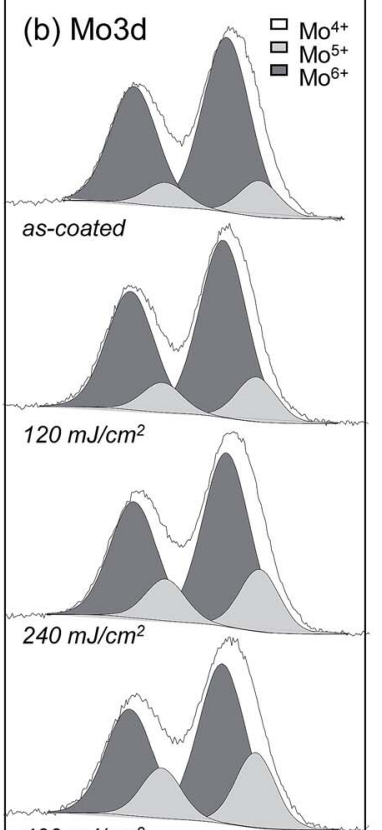

$400 \mathrm{~mJ} / \mathrm{cm}^{2}$

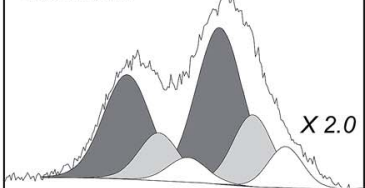

$600 \mathrm{~mJ} / \mathrm{cm}^{2}$

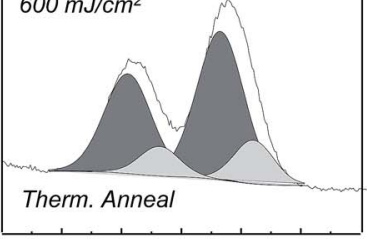

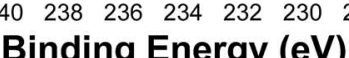

(c) N1s
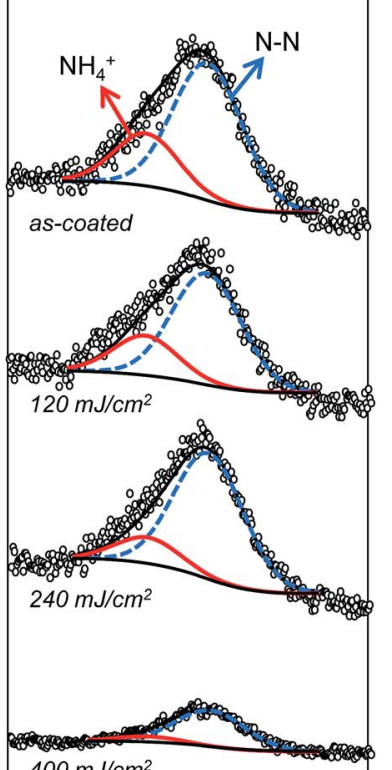

$400 \mathrm{~mJ} / \mathrm{cm}^{2}$

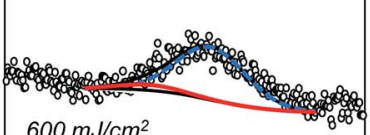

$600 \mathrm{~mJ} / \mathrm{cm}^{2}$

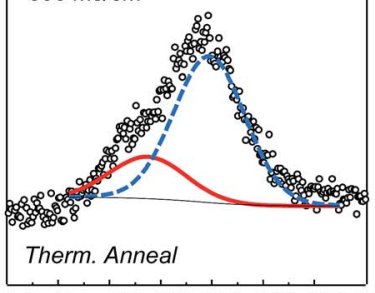

406404402400398396394392

Binding Energy (eV)

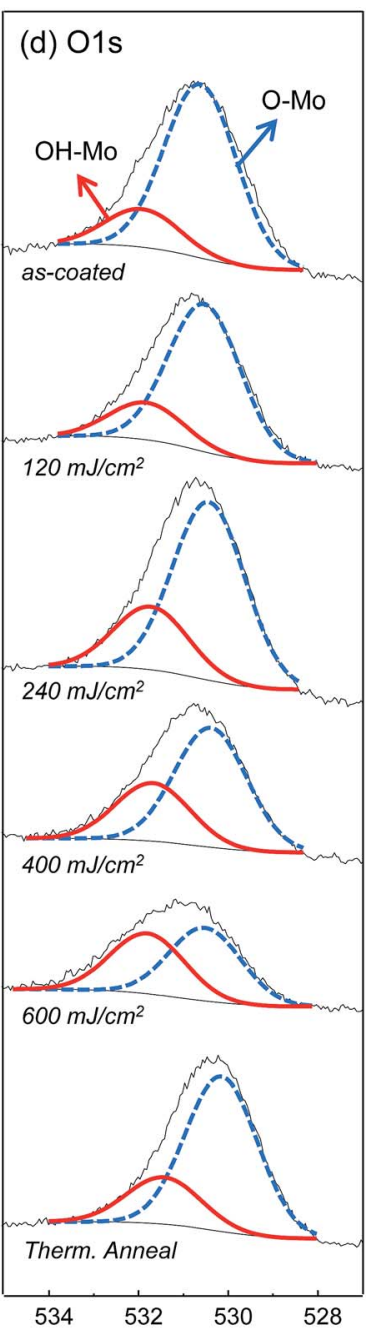

Binding Energy (eV)

Fig. 2 (a) FT-IR spectra, (b) Mo3d, (c) N1s and (d) O1s XPS spectra of the as-coated, laser-irradiated and thermally-annealed MoO 3 layers. The precursor concentration of $\mathrm{MoO}_{3}$ solution was $0.1 \mathrm{wt} \%$ and the measured thickness was $3 \mathrm{~nm}$. 
Table 1 Summary of atomic compositions of $\mathrm{MoO}_{3}$ for various laser energies and thermal annealing

\begin{tabular}{|c|c|c|c|c|c|c|c|}
\hline \multirow[b]{2}{*}{ Laser energy $\left(\mathrm{mJ} \mathrm{cm}^{-2}\right)$} & \multicolumn{3}{|l|}{ Mo3d } & \multicolumn{2}{|l|}{ O1s } & \multicolumn{2}{|l|}{ N1s } \\
\hline & $\mathrm{Mo}^{6+}$ & $\mathrm{Mo}^{5+}$ & $\mathrm{Mo}^{4+}$ & O-Mo & $\mathrm{OH}-\mathrm{Mo}$ & $\mathrm{N}-\mathrm{N}$ & $\mathrm{NH}^{4+}$ \\
\hline As-coated & $88 \%$ & $12 \%$ & $0 \%$ & $91 \%$ & $9 \%$ & $72 \%$ & $28 \%$ \\
\hline 120 & $88 \%$ & $12 \%$ & $0 \%$ & $89 \%$ & $11 \%$ & $74 \%$ & $26 \%$ \\
\hline 240 & $83 \%$ & $17 \%$ & $0 \%$ & $86 \%$ & $14 \%$ & $83 \%$ & $17 \%$ \\
\hline 400 & $79 \%$ & $21 \%$ & $0 \%$ & $81 \%$ & $19 \%$ & $87 \%$ & $13 \%$ \\
\hline 600 & $68 \%$ & $21 \%$ & $11 \%$ & $67 \%$ & $33 \%$ & $91 \%$ & $9 \%$ \\
\hline Thermal annealing & $92 \%$ & $8 \%$ & $0 \%$ & $91 \%$ & $9 \%$ & $81 \%$ & $19 \%$ \\
\hline
\end{tabular}
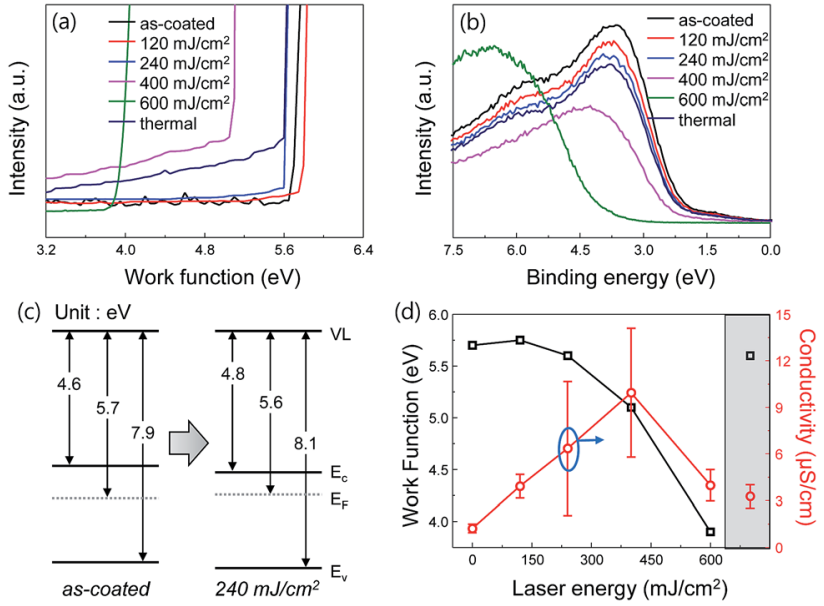

Fig. 3 (a) Secondary electron emission spectra and (b) valence band spectra of $\mathrm{MoO}_{3}$ layers. (c) Schematic energy band diagram of ascoated and laser-irradiated $\mathrm{MoO}_{3}$ layers. (d) Work function and electrical conductivity vs. laser energy. Shaded region: results of the thermally annealed sample.

mode of Mo-O-H and deformation mode of Mo-O- $\mathrm{H}$ bonds $(\delta \mathrm{Mo}-\mathrm{OH})$, respectively. ${ }^{28-30}$ As the laser energy increased, the bands of the terminal oxygen $\left(\nu \mathrm{O}=\mathrm{Mo}, 949 \mathrm{~cm}^{-1}\right)$ and $\mathrm{Mo}-\mathrm{O}-$ Mo ( 831 and $883 \mathrm{~cm}^{-1}$ ) disappeared while the intensity of the band between 752 and $798 \mathrm{~cm}^{-1}(\nu \mathrm{Mo}-\mathrm{O})$ and the band above $1120 \mathrm{~cm}^{-1}$ (Mo-O-H) increased. The thermally annealed $\mathrm{MoO}_{3}$ layer prepared at $150{ }^{\circ} \mathrm{C}$ for $10 \mathrm{~min}$ on hot plate, exhibited the band of terminal oxygen at $949 \mathrm{~cm}^{-1}$, which is evidence that less Mo was reduced than in the sample treated by laser irradiation at $240 \mathrm{~mJ} \mathrm{~cm}^{-2}$. We propose that the laser-assisted reaction of $\mathrm{MoO}_{3}$ proceeds as follows: excess hydrogen atoms produced by the decomposition of $\mathrm{NH}_{4}{ }^{+}$react with $\mathrm{MoO}_{3}$, thereby converting the terminal oxygen $(\mathrm{Mo}=\mathrm{O})$ to hydroxyl groups $(\mathrm{Mo}-\mathrm{OH})$. This reaction reduces the $\mathrm{Mo}^{6+}$ to $\mathrm{Mo}^{5+}$ or $\mathrm{Mo}^{4+}$.

In order to characterize the stoichiometric composition of $\mathrm{MoO}_{3}$ in detail, the Mo3d spectrum was measured using synchrotron X-ray photoelectron spectroscopy (XPS) (Fig. 2b) and the atomic compositions of laser-irradiated and thermallyannealed $\mathrm{MoO}_{3}$ thin films were determined (Table 1). In a molybdenum oxide, the binding energies are centered at 233.0 $\mathrm{eV}$ for $\mathrm{Mo}^{6+}$, at $231.8 \mathrm{eV}$ for $\mathrm{Mo}^{5+}$, and at $230.8 \mathrm{eV}$ for $\mathrm{Mo}^{+}$. Deconvolution of the Mo3d spectrum reveals that they are fitted by doublets in the form of Gaussian functions. ${ }^{31,32}$ As the laser (a)

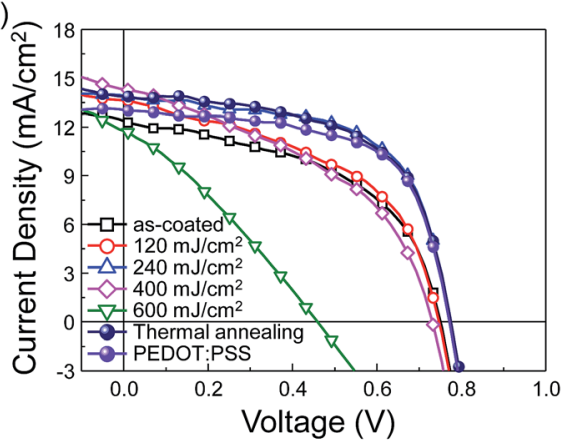

(b)

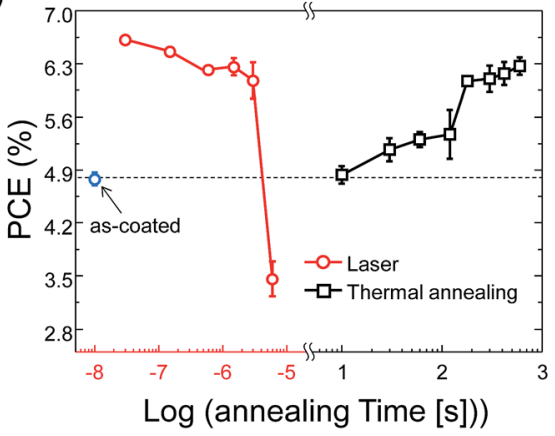

Fig. 4 (a) J-V characteristics of PTB7:PCBM bulk-heterojunction solar cells with $\mathrm{MoO}_{3}$ hole transport layers. (b) PCE of OSCs as a function of annealing time of $\mathrm{MoO}_{3}$. The laser energy was $240 \mathrm{~mJ} \mathrm{~cm}^{-2}$ for the laser-assisted reaction and the temperature was $150{ }^{\circ} \mathrm{C}$ for thermal annealing.

energy increased, the intensity of the $\mathrm{Mo}^{6+}$ peak decreased and the reduced state of the $\mathrm{Mo}^{5+}$ peak became apparent. Particularly, when the $\mathrm{MoO}_{3}$ layer was irradiated with high energy of $600 \mathrm{~mJ} \mathrm{~cm}{ }^{-2}$, the highly-reduced $\mathrm{Mo}^{4+}$ appeared. These $\mathrm{Mo}^{4+}$ ions resulted from an increased number of $\mathrm{Mo}-\mathrm{OH}$ bonds ${ }^{15}$ and the direct bonds of hydrogen atoms with Mo ions. ${ }^{33}$

The N1s XPS spectra (Fig. 2c) were deconvoluted to two peaks; one of $\mathrm{N}-\mathrm{N}(398.5 \mathrm{eV})$ and one of $\mathrm{NH}_{4}{ }^{+}(401 \mathrm{eV}){ }^{18}$ The $\mathrm{N}-\mathrm{N}$ bonds are associated with surface-adsorbed $\mathrm{N}$; the $\mathrm{NH}_{4}{ }^{+}$ represents the ammonium functional groups in the solutionprocessed $\mathrm{MoO}_{3}$ thin-film. As the laser energy increased, the $\mathrm{NH}_{4}{ }^{+}$peak gradually disappeared. We believe that the ammonium molecules at the surface decomposed to $\mathrm{NH}_{3}$ gas and $\mathrm{H}^{+}$ during laser irradiation. ${ }^{34}$ The $\mathrm{H}^{+}$reacts with double-bonded terminal oxygen atoms in $\mathrm{MoO}_{3}$. The reaction produces hydroxyl groups $(-\mathrm{OH})$ in the $\mathrm{MoO}_{3}$ thin-film as indicated in the 
O1s XPS spectra (Fig. 2d). The XPS O1s spectra of the as-coated $\mathrm{MoO}_{3}$ shows a peak at $530.6 \mathrm{eV}$, which is assigned to the Mo-O bond. ${ }^{17}$ As the laser energy was increased, an extra peak of hydroxyl groups $(-\mathrm{OH})$ at the binding energy of $532 \mathrm{eV}$ increased gradually. These XPS results indicate that the $\mathrm{MoO}_{3}$ layer was hydrogenated to form hydrogenated molybdenum oxide $\left(\mathrm{H}_{y^{-}}\right.$ $\left.\mathrm{MoO}_{3-x}\right)$. In the thermally annealed sample, the Mo3d, N1s and O1s spectra show a similar atomic composition to the $\mathrm{MoO}_{3}$ thin films that had been irradiated at $120 \mathrm{~mJ} \mathrm{~cm}^{-2}$.

\subsection{Electrical properties of reduced $\mathrm{MoO}_{3}$}

The secondary electron emission spectra (Fig. 3a) show the WF of the $\mathrm{MoO}_{3}$ thin-film after irradiation at various laser energies, or after thermal annealing. As the laser energy increased, the WF decreased because many of the Mo cations were reduced to $\mathrm{Mo}^{5+}$ and $\mathrm{Mo}^{4+}$, which have a small electronegativity. ${ }^{31,32}$ The valence band maximum (VBM) was located at $2.2 \mathrm{eV}$ for the ascoated $\mathrm{MoO}_{3}$ thin-film, but gradually increased to $4.0 \mathrm{eV}$ in the sample with that had been irradiated at $600 \mathrm{~mJ} \mathrm{\textrm {cm } ^ { - 2 }}$ (Fig. 3b).

The band diagrams of the as-coated and laser-irradiated $\mathrm{MoO}_{3}$ thin films (Fig. 3c) were determined from the secondary electron emission spectra and valence band spectra. The WF of $\mathrm{MoO}_{3}$ decreased and the valence bands shifted to higher binding energy as the laser energy increased; as a result, the Fermi level $\left(E_{\mathrm{F}}\right)$ of the reduced $\mathrm{MoO}_{3}$ shifted toward the conduction band edge $\left(E_{\mathrm{c}}\right)$, thereby resulting in an n-type doping effect. The shift of $E_{\mathrm{F}}$ is attributed to the increased number of free electrons. The WF varied quadratically with laser

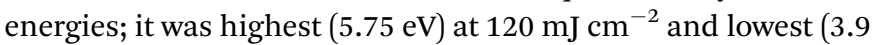
$\mathrm{eV}$ ) at $600 \mathrm{~mJ} \mathrm{~cm}^{-2}$ (Fig. 3d). In contrast, the average electrical conductivity increased from $1.2 \mu \mathrm{S} \mathrm{cm}^{-1}$ to $9.9 \mu \mathrm{S} \mathrm{cm} \mathrm{cm}^{-1}$ at 400 $\mathrm{mJ} \mathrm{cm}{ }^{-2}$. The samples treated at $240 \mathrm{~mJ} \mathrm{~cm}^{-2}$ and $400 \mathrm{~mJ} \mathrm{~cm}^{-2}$, had a higher average electrical conductivity than the thermally annealed samples. In the sample treated at $600 \mathrm{~mJ} \mathrm{~cm}^{-2}$, the electrical conductivity decreased due to degradation of the ITO electrode.

\subsection{Ultrafast reaction of the $\mathrm{MoO}_{3}$ hole transport layer for organic solar cells}

In order to demonstrate the laser-irradiated $\mathrm{MoO}_{3}$ layer as a hole transport layer (HTL) in organic solar cells, PTB7:PCBM bulk-heterojunction solar cells were fabricated on ITO-coated glass substrates. Current density-voltage $(J-V)$ curves (Fig. 4a) and device parameters (Table 2) were obtained for devices with as-coated $\mathrm{MoO}_{3}$, laser-irradiated $\mathrm{MoO}_{3}$, thermally annealed $\mathrm{MoO}_{3}$, and PEDOT:PSS. The device with the ascoated $\mathrm{MoO}_{3}$ had an open circuit voltage $\left(V_{\text {oc }}\right)=0.75 \mathrm{~V}$, shortcircuit current $\left(J_{\mathrm{sc}}\right)=12.5 \mathrm{~mA} \mathrm{~cm}^{-2}$, fill factor $(\mathrm{FF})=50.3 \%$ and low PCE $=4.7 \%$. After laser irradiation $\left(240 \mathrm{~mJ} \mathrm{~cm}^{-2}\right)$ of the $\mathrm{MoO}_{3}$ layer, the PCE increased to the maximum value of $6.6 \%$, which was higher than the PCE of the control devices with PEDOT:PSS HTL (PCE $=6.3 \%$ ) and the device with thermally-annealed $\mathrm{MoO}_{3}(\mathrm{PCE}=6.4 \%)$. The enhancement of PCE is mainly ascribed to the increases in $J_{\mathrm{sc}}$ and FF, which occurred as a consequence of the increase in electrical conductivity. When the laser energy of $400 \mathrm{~mJ} \mathrm{~cm}{ }^{-2}$ is used, the PCE decreased to $4.6 \%$ due to a low WF $(5.1 \mathrm{eV})$. When the laser energy increased to $600 \mathrm{~mJ} \mathrm{~cm}^{-2}$, the PCE further decreased to $1.6 \%$. This is due to the WF being reduced to $3.9 \mathrm{eV}$ and an excess of hydrogen ions are produced to form Mo-H bonds, having a role in trapping the charge carriers. ${ }^{33}$

To compare the reaction time of the laser-assisted reaction and conventional thermal annealing, OSCs were fabricated with precursors annealed for various durations (Fig. S3 and Table $\mathrm{S} 1 \dagger)$. The annealing time of the laser-assisted reaction was controlled by adjusting the number of laser pulses with a frequency of $2 \mathrm{~Hz}$ and a pulse duration of $30 \mathrm{~ns}$. Thermal annealing was conducted at $150{ }^{\circ} \mathrm{C}$ on a hot plate. When the $\mathrm{MoO}_{3}$ layer was irradiated with energy of $240 \mathrm{~mJ} \mathrm{~cm}{ }^{-2}$, the efficiency of the OSCs drastically increased and reached a maximum PCE value of $6.6 \%$ within 30 ns (Fig. $4 \mathrm{~b}$, red). In contrast, the thermal annealing of $\mathrm{MoO}_{3}$ slowly increased the efficiency of the OSCs (Fig. 4b, black). The annealing duration required to achieve an efficiency of $6.1 \%$ was $3 \mathrm{~min}$. These results verify that the laser-assisted reaction dramatically reduces the fabrication time compared to conventional thermal annealing. The structure of the $\mathrm{MoO}_{3}$ changes with annealing time (Fig. $\mathrm{S} 4 \dagger$ ).

\subsection{Flexible top-illuminated organic solar cells}

Flexible top-illuminated PTB7:PCBM-based organic solar cells were fabricated on flexible polyethylene sulfone (PES) films; the device structure of the top-illuminated solar cell was: PES film/

Table 2 Photovoltaic characteristics of the devices with various HTLs. The illumination condition used for the measurements was AM $1.5 \mathrm{G} 100$ $\mathrm{mW} \mathrm{cm} \mathrm{cm}^{-2}$

\begin{tabular}{lllllll}
\hline HTL & $V_{\text {oc }}(\mathrm{V})$ & $J_{\text {sc }}\left(\mathrm{mA} \mathrm{cm}^{-2}\right)$ & FF $(\%)$ & PCE $(\%)$ & WF $(\mathrm{eV})$ & Average $\left.\sigma(\mu \mathrm{S} \mathrm{cm})^{-1}\right)$ \\
\hline As-coated & 0.75 & 12.5 & 50.3 & 4.72 & 5.7 & 1.2 \\
$120 \mathrm{~mJ} \mathrm{~cm}^{-2}$ & 0.75 & 13.7 & 49.8 & 5.12 & 5.75 & 3.9 \\
$240 \mathrm{~mJ} \mathrm{~cm}^{-2}$ & 0.77 & 13.9 & 61.2 & 6.55 & 5.6 & 6.3 \\
$400 \mathrm{~m} \mathrm{~cm}^{-2}$ & 0.73 & 14.3 & 44.4 & 4.63 & 5.1 & 3.9 \\
$600 \mathrm{~mJ} \mathrm{~cm}^{-2}$ & 0.45 & 11.9 & 30.2 & 1.62 & 5.6 & 3.9 \\
Thermal annealing & 0.77 & 13.8 & 60.2 & 6.43 & - & -
\end{tabular}


(a)

(b)
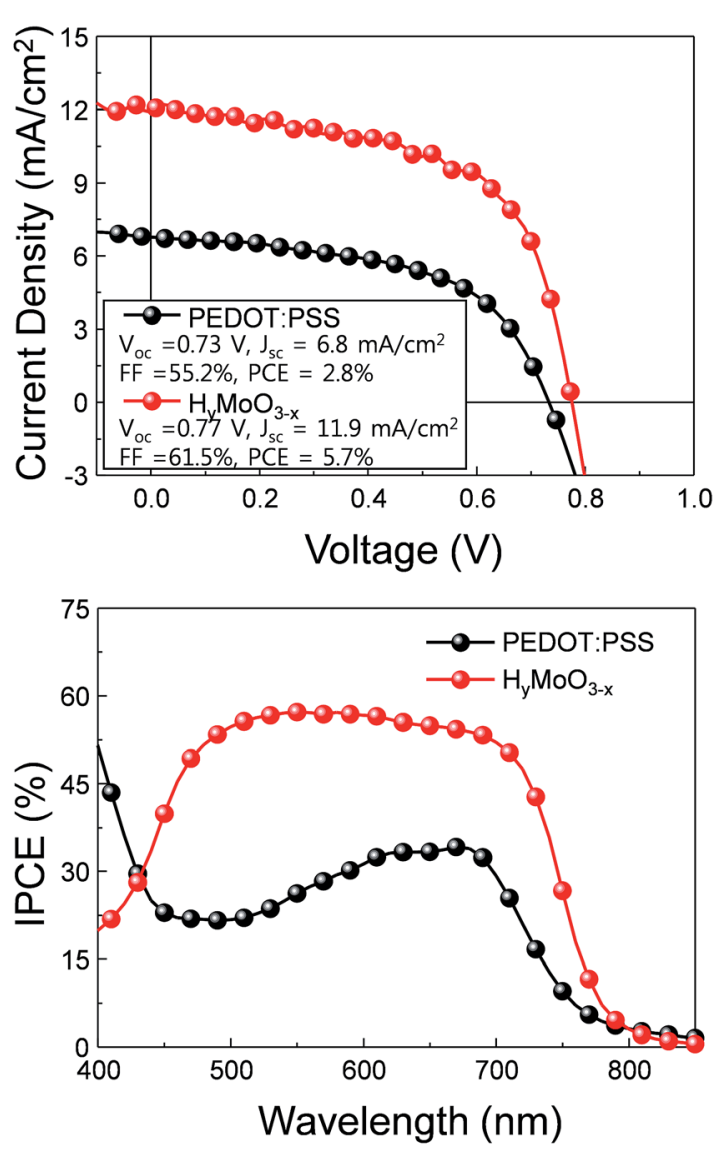

(c)

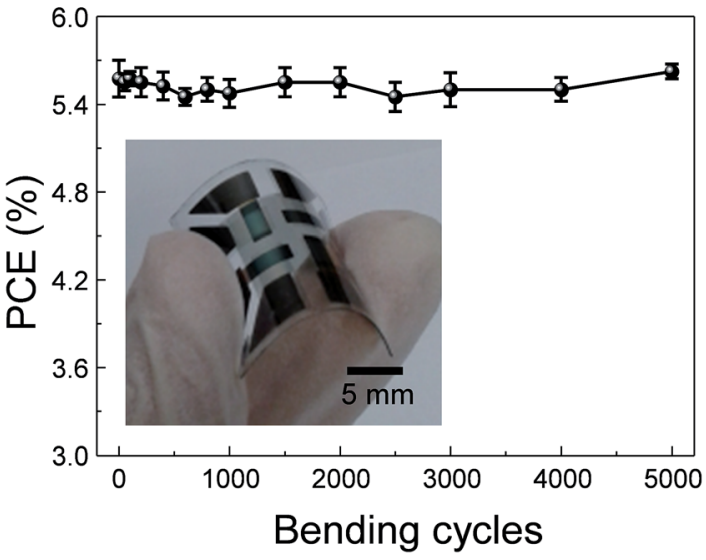

Fig. 5 (a) J-V curves and (b) IPCE spectra of flexible top-illuminated OSCs. Device structure of flexible OSCs: PES film/Ag (120 nm)/ITO (20 $\mathrm{nm}) / \mathrm{HTL} / \mathrm{PTB} 7: \mathrm{PCBM}(80 \mathrm{~nm}) / \mathrm{BCP}(15 \mathrm{~nm}) / \mathrm{Ag}(12 \mathrm{~nm}) / \mathrm{MoO}_{3}(40 \mathrm{~nm})$. (c) Change in photo-conversion efficiency (PCE) by bending cycles at a radius of $0.48 \mathrm{~cm}$.

$\mathrm{Ag} \quad(120 \mathrm{~nm}) / \mathrm{ITO} \quad(20 \mathrm{~nm}) / \mathrm{HTL} / \mathrm{PTB} 7: \mathrm{PCBM} \quad(80 \mathrm{~nm}) / \mathrm{BCP}$ $(15 \mathrm{~nm}) / \mathrm{Ag}(12 \mathrm{~nm}) / \mathrm{MoO}_{3}(40 \mathrm{~nm})$. The thin ITO $(20 \mathrm{~nm})$ was inserted between the Ag layer and the solution-processed HTL to allow wetting of the $\mathrm{MoO}_{3}$ and PEDOT:PSS solution on the hydrophobic $\mathrm{Ag}$ reflector. The device with $\mathrm{H}_{y} \mathrm{MoO}_{3-x}$ had a higher $J_{\text {sc, }}$ FF and $V_{\text {oc }}$ than the device based on PEDOT:PSS (Fig. 5a). The flexible OSCs with $\mathrm{H}_{y} \mathrm{MoO}_{3-x}$ had a much higher $\mathrm{PCE}=5.7 \%$ than the control device with PEDOT:PSS (PCE $=$
2.8\%). The high efficiency of OSCs with $\mathrm{H}_{y} \mathrm{MoO}_{3-x}$ can be attributed to its higher short-circuit current $\left(11.9 \mathrm{~mA} \mathrm{~cm} \mathrm{~cm}^{-2}\right)$ compared to that of the device with PEDOT:PSS $\left(6.8 \mathrm{~mA} \mathrm{~cm}^{-2}\right)$. The incident photon-to-current efficiency (IPCE) (Fig. 5b) was measured to determine the reason for the efficiency increase. The OSCs fabricated with the PEDOT:PSS HTL had a small IPCE, but the device with the $\mathrm{H}_{y} \mathrm{MoO}_{3-x}$ layer generated a large amount of photocurrent in the visible spectrum region $(400 \leq \lambda$ $\leq 800 \mathrm{~nm}$ ). This result demonstrates that the thin $\mathrm{H}_{y} \mathrm{MoO}_{3-x}$ layer (3 nm) absorbs light much more efficiently than the thick PEDOT:PSS layer (40 nm). The mechanical flexibility of the OSCs was characterized in a bending cycle test. The flexible topilluminated OSCs fabricated on the PES film did not lose efficiency even after 5000 bending cycles with a radius of $0.48 \mathrm{~cm}$ (Fig. 5c).

The contour of light absorption in top-illuminated OSCs was characterized by optical simulation to verify the effect of thin HTLs on the increase in light absorption. Assuming that the light strikes the surface in the normal direction, an optical simulation was conducted using the finite-difference timedomain (FDTD) simulation. When the PEDOT:PSS was used as the HTL in OSCs (Fig. 6a), the wavelength at which light absorption was highest positions at a long wavelength $(720 \mathrm{~nm})$, and the contour diverged from the center of the PTB7:PCBM active layer. The contour of external quantum efficiency (EQE) is plotted by multiplying absorption and internal quantum efficiency. Because the peak wavelength of the EQE $(710 \mathrm{~nm})$ is far from the absorption region of the active layer (400-700 nm) (Fig. 6a) and the IQE (Fig. S5†) rapidly drops above $700 \mathrm{~nm}$, OSCs with PEDOT:PSS cannot efficiently generate a photocurrent from the absorbed photons, resulting in a low EQE. In contrast, the OSCs with the $\mathrm{H}_{y} \mathrm{MoO}_{3-x}$ layer (Fig. 6b) strongly absorbed photons on a broad range of the visible spectrum (500 $\mathrm{nm}<\lambda<700 \mathrm{~nm}$ ) where both the absorbance and IQE of PTB7:PCBM are simultaneously large. The peak of the EQE $(610 \mathrm{~nm})$ is positioned at the center of the PTB7:PCBM active layer. Therefore, the calculated EQE of the devices with $\mathrm{H}_{y} \mathrm{MoO}_{3-x}$ is larger than the cells with PEDOT:PSS. The large difference in the EQE of these two devices results from an optical microcavity. Because the distance between the top semi-transparent $\mathrm{Ag}$ layer and the bottom reflective $\mathrm{Ag}$ electrode determines the resonant wavelength of the microcavity in the active layer, the HTL (PEDOT:PSS or $\mathrm{H}_{y} \mathrm{MoO}_{3-x}$ ) plays a role as an optical spacer, which affects light absorption in the device. The low efficiency of OSCs with PEDOT:PSS can be explained by the long distance between two $\mathrm{Ag}$ reflectors. In order to fit the resonant wavelength of OSCs with PEDOT:PSS to the center of the absorbance spectrum of PTB7:PCBM, the thickness of the active layer should be reduced to $45 \mathrm{~nm}$ (Fig. S6†), resulting in broadband light absorption. However, the total absorption of light was decreased because the thin PTB7:PCBM layer (45 nm) is not enough to absorb incident photons compared to the thick PTB7:PCBM layer $(80 \mathrm{~nm})$. This provides evidence that the light absorption in OSCs with a PEDOT:PSS layer could not overcome that in top-illuminated OSCs with a $\mathrm{H}_{y} \mathrm{MoO}_{3-x}$ one, even though the microcavity was optimized. 

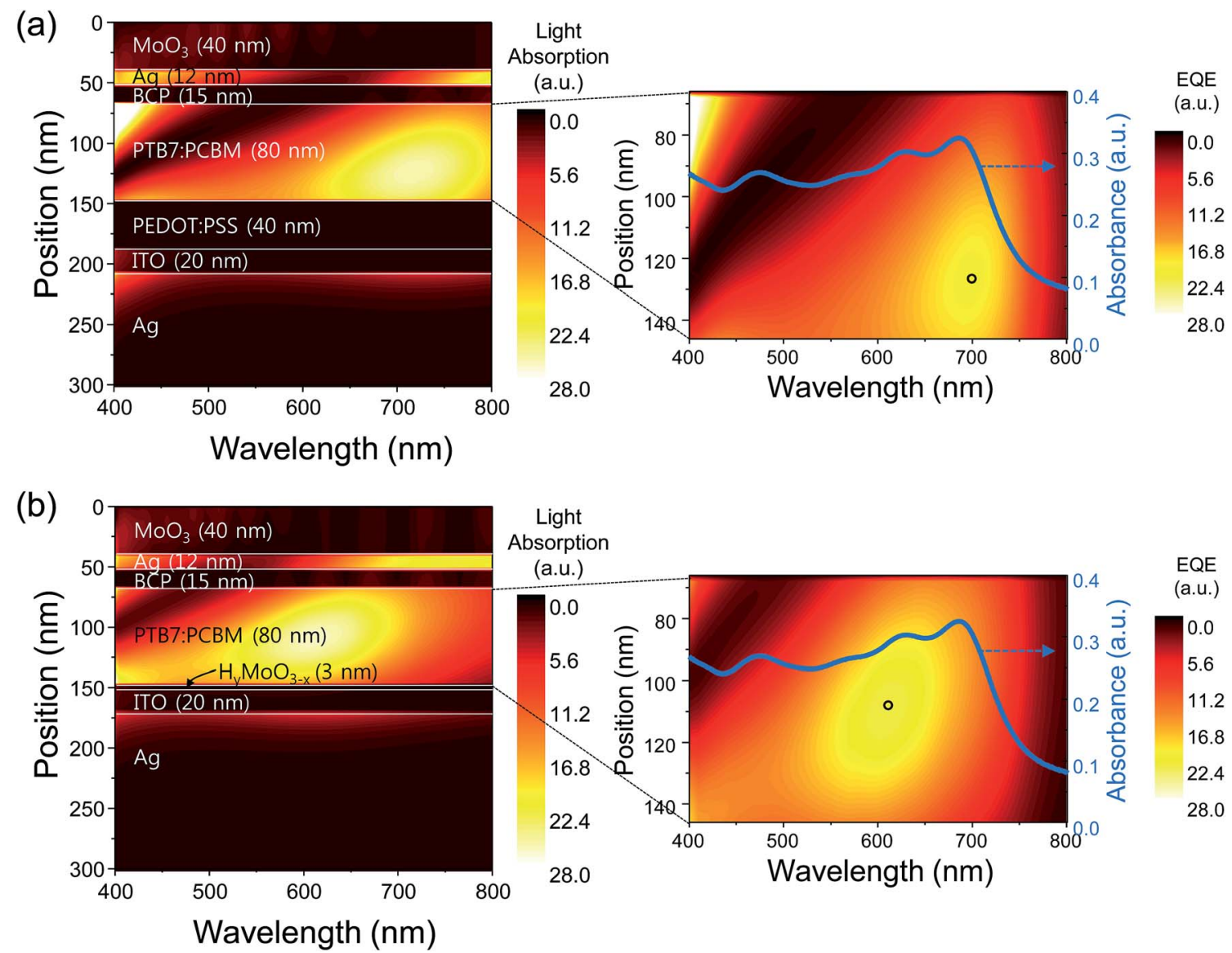

Fig. 6 2-Dimensional contour of light absorption and calculated EQEs in top-illuminated OSCs with (a) PEDOT:PSS and (b) $\mathrm{H}_{y} \mathrm{MoO}_{3-x} \mathrm{HTLS}$ Absorbance of PTB7:PCBM is plotted on the right figure.

\section{Conclusions}

In summary, an ultrafast laser-assisted reaction of hydrogenated molybdenum oxide $\left(\mathrm{H}_{y} \mathrm{MoO}_{3-x}\right)$ thin films was demonstrated. The stoichiometry of the $\mathrm{H}_{y} \mathrm{MoO}_{3-x}$ layer was controlled by laser energy, thereby resulting in beneficial electronic properties such as high WF $(5.6 \mathrm{eV})$ and electrical conductivity $\left(9.9 \mu \mathrm{S} \mathrm{cm}^{-1}\right)$. When the laserassisted reaction was conducted for the preparation of hole transport layers for organic solar cells, the annealing time was reduced by a factor of $10^{9}$ compared to conventional thermal annealing. The $\mathrm{H}_{y} \mathrm{MoO}_{3-x}$ HTL was effective not only for charge transport but also for light trapping in flexible top-illuminated OSCs. A flexible device with $\mathrm{H}_{y} \mathrm{MoO}_{3-x}$ exhibited enhancement of the short-circuit current by $75 \%$ compared to the device with PEDOT:PSS. The optical simulation verifies that the thin layer of $\mathrm{H}_{y} \mathrm{MoO}_{3-x}(3 \mathrm{~nm})$ is effective for light absorption in the microcavity, where the resonant wavelength matches with the absorption band of PTB7:PCBM. This laser-assisted low-temperature and ultrafast reaction method can be conducted for other transition metal oxides, and is suitable for R2R fabrication of flexible electronics.

\section{Acknowledgements}

This work was supported by the National Research Foundation of Korea (NRF) grant funded by the Korea government (MSIP) (No. NRF-2013R1A2A2A01069237).

\section{References}

1 K.-G. Lim, S. M. Park, H. Y. Woo and T.-W. Lee, ChemSusChem, 2015, 8, 3062.

2 D.-H. Kim, K.-G. Lim, J. H. Park and T.-W. Lee, ChemSusChem, 2012, 5, 2053.

3 M.-R. Choi, T.-H. Han, K.-G. Lim, S.-H. Woo, D. H. Huh and T.-W. Lee, Angew. Chem., Int. Ed., 2011, 50, 6274.

4 H. J. Bolink, E. Coronado, J. Orozco and M. Sessolo, Adv. Mater., 2009, 21, 79.

5 Z. He, C. Zhong, S. Su, M. Xu, H. Wu and Y. Cao, Nat. Photonics, 2012, 6, 591.

6 G. Li, R. Zhu and Y. Yang, Nat. Photonics, 2012, 6, 153.

7 S. Chen, J. R. Manders, S.-W. Tsang and F. So, Adv. Mater., 2012, 22, 24202.

8 V. Shrotriya, G. Li, Y. Yao, C.-W. Chu and Y. Yang, Appl. Phys. Lett., 2006, 88, 073508. 
9 J.-Y. Jeng, K.-C. Chen, T.-Y. Chiang, P.-Y. Lin, T.-D. Tsai, Y.-C. Chang, T.-F. Guo, P. Chen, T.-C. Wen and Y.-J. Hsu, Adv. Mater., 2014, 24, 4107.

10 F. Liu, S. Shao, X. Guo, Y. Zhao and Z. Xie, Sol. Energy Mater. Sol. Cells, 2010, 94, 842.

11 J. Meyer, R. Khalandovsky, P. Gorrn and A. Kahn, Adv. Mater., 2011, 23, 70.

12 C. Girotto, E. Voroshazi, D. Cheyns, P. Heremans and B. P. Rand, ACS Appl. Mater. Interfaces, 2011, 3, 3244.

13 S. R. Hammond, J. Meyer, N. E. Widjonarko, P. F. Ndione, A. K. Sigdel, A. Garcia, A. Miedaner, M. T. Lloyd, A. Kahn, D. S. Ginley, J. J. Berry and D. C. Olson, J. Mater. Chem., 2012, 22, 3249.

14 F. Xie, W. C. H. Choy, C. Wang, X. Li, S. Zhang and J. Hou, Adv. Mater., 2013, 25, 2051.

15 M. Vasilopoulou, A. M. Douvas, D. G. Georgiadou, L. C. Palilis, S. Kennou, L. Sygellou, A. Soultati, I. Kostis, G. Papadimitropoulos, D. Davazoglou and P. Argitis, J. Am. Chem. Soc., 2012, 134, 16178.

16 A. Soultati, A. M. Douvas, D. G. Georgiadou, L. C. Palilis, T. Bein, J. M. Feckl, S. Gardelis, M. Fakis, S. Kennou, P. Falaras, T. Stergiopoulos, N. A. Stathopoulos, D. Davazoglou, P. Argitis and M. Vasilopoulou, Adv. Energy Mater., 2014, 4, 1300896.

17 S. Murase and Y. Yang, Adv. Mater., 2012, 24, 2459.

18 J. Griffin, A. J. Pearson, N. W. Scarratt, T. Wang, D. G. Lidzey and A. R. Buckley, Org. Electron., 2014, 15, 692.

19 J. J. Jasieniak, J. Seifter, J. Jo, T. Mates and A. J. Heeger, Adv. Funct. Mater., 2012, 22, 2594.

20 Y.-J. Lee, J. Yi, G. F. Gao, H. Koerner, K. Park, J. Wang, K. Luo, R. A. Vaia and J. W. P. Hsu, Adv. Energy Mater., 2012, 2, 1193.
21 W. J. Dong, G. H. Jung and J.-L. Lee, Sol. Energy Mater. Sol. Cells, 2013, 116, 94.

22 C. Yao, X. Xu, J. Wang, L. Shi and L. Li, ACS Appl. Mater. Interfaces, 2013, 5, 1100.

23 K. Zilberberg, H. Gharbi, A. Nehrendt, S. Trost and T. Riedl, ACS Appl. Mater. Interfaces, 2012, 4, 1164.

24 W. Qiu, A. Hadipour, R. Muller, B. Conings, H.-G. Boyen, P. Heremans and L. Froyen, ACS Appl. Mater. Interfaces, 2014, 6, 16335.

25 J. Wang, J. Zhang, B. Meng, B. Zhang, Z. Xie and L. Wang, ACS Appl. Mater. Interfaces, 2015, 7, 13590.

26 X. Li, F. Xie, S. Zhang, J. Hou and W. C. H. Choy, Light: Sci. Appl., 2015, 4, e273.

27 H. Cheng, T. Kamegawa, K. Mori and H. Yamashita, Angew. Chem., Int. Ed., 2014, 53, 2910.

28 T. Weber, J. C. Muijsers, J. H. M. C. van Wolput, C. P. J. Verhagen and J. W. Niemantsverdriet, J. Phys. Chem., 1996, 100, 14144.

29 M. Dhanasankar, K. K. Purushothaman and G. Muralidharan, Appl. Surf. Sci., 2011, 257, 2074.

30 T. H. Chiang and H. C. Yeh, Materials, 2013, 6, 4609.

31 M. T. Greiner, L. Chai, M. G. Helander, W.-M. Tang and Z.-H. Lu, Adv. Funct. Mater., 2013, 23, 215.

32 M. T. Greiner, L. Chai, M. G. Helander, W.-M. Tang and Z.-H. Lu, Adv. Funct. Mater., 2012, 22, 4557.

33 I. Kostis, N. Vourdas, G. Papadimitropoulos, A. Douvas, M. Vasilopoulou, N. Boukos and D. Davazoglou, J. Phys. Chem. C, 2013, 117, 18013.

34 P. Pichat, M.-N. Mozzanega and C. Hoang-Van, J. Phys. Chem., 1988, 92, 467. 